Review Article

\title{
Policies and Problems of Modernizing Ethnomedicine in China: A Focus on the Yi and Dai Traditional Medicines of Yunnan Province
}

\author{
Zhiyong Li $\mathbb{D}^{1,2,3}$ Caifeng Li, ${ }^{4}$ Xiaobo Zhang, ${ }^{5}$ Shihuan Tang, ${ }^{6}$ Hongjun Yang $\left(\mathbb{D},{ }^{6}\right.$ \\ Xiuming Cui, ${ }^{1}$ and Luqi Huang $\mathbb{D}^{5}$ \\ ${ }^{1}$ Faculty of Life Science and Technology, Kunming University of Science and Technology, Kunming, Yunnan, China \\ ${ }^{2}$ School of Pharmacy, Minzu University of China, Beijing, China \\ ${ }^{3}$ Yunnan Province Resources of Development and Collaborative Innovation Center for New Traditional Chinese Medicine, \\ Kunming, Yunnan, China \\ ${ }^{4}$ Jiangxi University of Traditional Chinese Medicine, Nanchang, Jiangxi, China \\ ${ }^{5}$ State Key Laboratory Breeding Base of Dao-Di Herbs, National Resource Center for Chinese Materia Medica, \\ China Academy of Chinese Medical Sciences, Beijing, China \\ ${ }^{6}$ Institute of Chinese Materia Medica, China Academy of Chinese Medical Sciences, Beijing, China
}

Correspondence should be addressed to Luqi Huang; huangluqi01@126.com

Received 1 March 2020; Revised 23 May 2020; Accepted 22 June 2020; Published 14 August 2020

Academic Editor: Vincenzo De Feo

Copyright (c) 2020 Zhiyong Li et al. This is an open access article distributed under the Creative Commons Attribution License, which permits unrestricted use, distribution, and reproduction in any medium, provided the original work is properly cited.

Yunnan is a multiethnic province in southwest China, rich in Materia medica resources, and is popularly known as the kingdom of plants. Biomedicine and public health industry have been the industrial pillars of Yunnan since 2016, which is the important pharmaceutical industrial base for Dai and Yi medicine in China. This review of the Yunnan ethnic medicine industry describes some of the problems to be solved in the development of sustainable ethnomedicine in China. We investigated Chinese patent medicines (CPMs) declared as ethnomedicine on the drug instructions and identified 28 Dai patent medicines (DPMs) and 73 Yi patent medicines (YPMs) that were approved for clinical use in China. In further research, the clinical indications of these CPMs were determined, and the quality standard of medicinal materials and their usage frequencies in DPMs and YPMs were investigated. We also collected and analyzed the data on use of botanical and animal sources of medicines, the rare and endangered medicinal materials, and toxic medicines in DPMs and YPMs. The application of zootherapy in Yi traditional medicine was introduced from its abundant ancient documents and records; based on the "YaGei" theory in Dai traditional medicine, toxic medicines can be relatively safe in DPMs. However, for promoting the Yunnan traditional medicine industry, it is necessary to strengthen medical research to expand evidence-based clinical practice and balance ethnomedicine production and sustainable utilization of Materia medica resources, especially the animal sources of medicines, toxic medicines, and the protected wild resources reported in this survey. Only in this way can industrialization of ethnomedicine promote the improvement of human health.

\section{Introduction}

Evidence of the first human use of plants as medicines was observed in the fossil record of the Middle Paleolithic period, which began approximately 60,000 years ago [1]. Traditional medical knowledge and practices developed in different civilizations by the trial-and-error use of local botanicals and other biomaterial resources that accumulated slowly over long periods of time [2]. The World Health Organization
(WHO) estimates that herbal medicines currently serve the health needs of approximately $80 \%$ of the world's population, especially millions of people living in the vast rural areas of developing countries [3]. The Chinese have one of the oldest and distinct medical systems in the world. Traditional Chinese Medicine (TCM) has a written history of nearly 3000 years and is widely practiced in China [4]. China is a multiracial country with 56 nationalities, 55 of which are officially recognized as ethnic minorities in 18 provinces of 
China. Each ethnic minority, e.g., the Tibetans, Mongols, Uygurs, Dai, Yi, and Miao, has its own traditional medicine, and each differs slightly in theory and practice from TCM. Ethnomedicine thus refers to the use of traditional medicine guided by the medical theory and practical experience of each ethnic minority [5]. Since 2017, the Law of the People's Republic of China on Traditional Chinese Medicine has given ethnomedicine a relatively independent status although it is considered as part of TCM. The importance of ethnomedicine has been increasing in China since 1951 as discussed in detail below. Chinese Traditional Medicine Statistics published in 2015 by the National Administration of Traditional Chinese Medicine of China and the Investigation and Analysis of Quality Standards of Ethnomedicines in Nine Provinces of China published in 2015 by the National Medical Products Administration of China listed 161 pharmaceutical enterprises that produced 4317 ethnic patent medicines (EPMs) and nearly 4000 in-hospital preparations of ethnomedicines used in 253 ethnic hospitals. A total of 39 EPMs were included in Chinese Pharmacopoeia (2015 edition). The fourth national survey of Chinese Materia medica resources is underway with the objective of determining the status of the available resources and investigating the modern value of herbal medicine including ethnic and folk medicines [6]. However, the national application of ethnic medicine in China is a complex issue that involves public policy, ethnic culture, livelihood status, regional economies, the protection of wild resources, etc.

Yunnan is a multiethnic province in southwest China. In addition to the Han nationality, there are 25 ethnic minorities with a population of more than 6,000 , including the Yi, Hani, Bai, Dai, Zhuang, Miao, Hui, and Tibetan. The population of ethnic minorities is estimated at over 16 million, accounting for $33.4 \%$ of the provincial total population. The Dai and Yi traditional medicine are the representatives of ethnomedicine practiced in Yunnan. Tibetan medicine as practiced in Shangri-La will be described in a subsequent review. Yunnan Province is an important pharmaceutical industry center for Dai medicine and $\mathrm{Yi}$ medicine. For example, Yunnan Baiyao, a highly effective patent medicine has originated from the ancient Yi prescription [5]. Biomedicine and public health industry have been the major industries in Yunnan since 2016, and more than 2000 ethnic medicinal resources and more than 10,000 folk prescriptions are native to Yunnan [7]. This review focuses on the Yi and Dai traditional medicine in Yunnan and the potential problems to be encountered in the development of policies favorable to ethnomedicine development.

\section{Historical Changes of Chinese Ethnomedicine Policies}

Since 1949, the Chinese government has successively introduced many policies to support and protect the development of ethnomedicine (Table 1). The Ethnic Minorities Health Work Plan of China published in 1951 recommended that native doctors who used herbs to cure diseases should be united and supported to the greatest extent. The Decision on
Health Reform and Development published in 1997 discussed how ethnomedicine should be mined, organized, summarized, and improved. The Decision on Further Strengthening Rural Health Work, published in 2002, promoted the development and organization of ethnomedicine resources and technologies in rural regions. For many years, ethnic folk doctors in rural areas provided care in very much the same way as barefoot doctors, a nickname for part-time paramedical workers in rural areas who were trained for simple diagnoses and treatments in the 1960s and 1970s. During that time, China's health services could not cover all areas of the country, and the need of ethnic and folk medical practices was tacitly accepted. At present, the Tibetan, Mongolian, Uygur, Dai, Kazakh, Korean, Zhuang, and Hui medicine have set up physician certification systems for special skill or knowledge to support ethnic folk doctors obtaining legal medical qualification through certain procedures. The Outline of a Strategic Plan for Development of Traditional Chinese Medicine (2016-2030) published by the State Council of China promotes the development of ethnomedicine.

The status of ethnomedicine in China experienced a cognitive change with the publication of the Regulations of the People's Republic of China on Traditional Chinese Medicine in 2003, which required that the administration of ethnomedicine should be implemented with compliance to the regulations that apply to TCM and established a close relationship between ethnomedicine and TCM. The law of the People's Republic of China on Traditional Chinese Medicine currently defines ethnomedicine as one part of TCM, sharing a history and development with TCM that conform to the united national culture of China. Yunnan Province has published policies and plans to regulate the development of its rich medicine resources in the autonomous prefectures of Xishuangbanna Dai, Chuxiong Yi, Diqing Tibet, Chuxiong Yi, and Xishuangbanna Dai between 2016 and 2030 [8].

\section{Ethnic Hospitals and Pharmaceutical Enterprises in Yunnan}

Yunnan Province has two Yi autonomous prefectures, including Chuxiong Yi and Honghe Hani Yi, and two Dai autonomous prefectures, including Xishuangbanna and Dehong Dai Jingpo. There are also $11 \mathrm{Yi}$ autonomous counties and 7 Dai autonomous counties. The Yunnan Traditional Yi Medicine Hospital, the largest Yi medical hospital in China, is located in Chuxiong City, Chuxiong Yi Autonomous Prefecture. More than 10 counties have Yi medical hospitals or outpatient departments located in villages and towns of Yunnan. Each of the two Dai autonomous prefectures has a large traditional Dai medicine hospital, the hospital of Dai traditional medicine of Xishuangbanna Dai Autonomous Prefecture and the hospital of Dai traditional medicine of Dehong Dai Jingpo Autonomous Prefecture. There are at least 6 Dai hospitals in several counties.

A total of 42 corporations are licensed to produce Dai patent medicines (DPMs) and Yi patent medicines (YPMs) 
TABLE 1: History of Chinese ethnomedicine policy.

\begin{tabular}{|c|c|c|}
\hline Time & Policy outline & Promulgator \\
\hline 1951 & Ethnic minorities health work plan of China & Unknown \\
\hline 1984 & Several opinions on strengthening ethnic minorities work & Ministry of Health and NEAC \\
\hline 1997 & Decision on health reform and development & CPC Central Committee and the State Council \\
\hline 2002 & Decision on further strengthening rural health work & CPC Central Committee and the State Council \\
\hline 2003 & Regulations of the People's Republic of China on traditional Chinese medicine & The State Council \\
\hline 2007 & Guiding opinions on strengthening the development of ethnomedicine & 11 ministries including NATCM \\
\hline 2017 & The law of the People's Republic of China on traditional Chinese medicine & NPC standing committee \\
\hline 2018 & Some opinions on strengthening the ethnomedicine work in the new era & 13 ministries including NATCM \\
\hline
\end{tabular}

NEAC: National Ethnic Affairs Commission of PRC (China); CPC Central Committee: the Central Committee of the Communist Party; NATCM: National Administration of Traditional Chinese Medicine of PRC (China); NPC: National People's Congress.

in China. Two corporations are located outside Yunnan Province. Twenty corporations are in Kunming City, nine corporations are in Chuxiong Yi Autonomous Prefecture, three corporations are in Yuxi City, and two corporations are in Dali Bai Autonomous Prefecture. Wenshan City, Zhaotong City, and Xishuangbanna Dai Autonomous Prefecture have one pharmaceutical manufacturer each. The companies include the Yunnan Baiyao Group, which is best known for producing Baibaodan, the original name of Yunnan Baiyao, which was invented by Qu Huanzhang (AD 1880-1938). It also produces more than 300 other patent medicines and 19 dosage forms including Shu Lie An Capsule, Qiancao Nao Tong Oral liquid, Gu Feng Ning Capsule, Shang Yi Aerosol, Tong Shu Capsule, and Zhong Tong Liniment. In 2014, Dihon Pharmaceutical Co. was purchased by Bayer, a large German pharmaceutical company, which was marked as a significant entry for Bayer into the TCM marketplace. Dihon produces Dan E Fu Kang Ointment, Gan Dan Qing Capsule, Yu Mai Kou Yan liquid, and Wei Fu Shu Capsule.

\section{Clinical Indications of Yi and Dai Medicines}

Based on the pharmaceutical instructions in which the properties of ethnic medicine were claimed, the clinical indications of DPMs and YPMs were surveyed and recorded, and 28 DPMs and 73 YPMs that could be approved for clinical use in China following the drug regulatory laws were identified. Fourteen DPMs such as Biao Re Qing Granule, Guan Tong Shu Oral liquid, and Hui Xue Sheng Capsule that have already been approved as over-the-counter (OTC) drugs accounted for $50 \%$ of the DPMs. The YPMs included 24 prescriptions such as Bai Bei Yi Fei Capsule, Chang Shu Zhi Xie Capsule, and Dan E Fu Kang Ointment, which have been approved as OTC drugs and account for $32.8 \%$ of the total YPMs. The information about these patent medicines is recorded in Tables S1 and S2. As shown in Figure 1, these DPMs and YPMs are used to treat respiratory, cardiovascular, mental, and neurological diseases among others. One example is Dan Deng Tong Nao Capsule (DDTN), of which Erigeron breviscapus (Vaniot) Hand. -Mazz (Dengzhanxixin), a component herb, has been recorded in the pattraleaf scripture of Dai traditional medicine for 2500 years. DDTN when combined with rehabilitation training can improve the recovery of neurological function and the

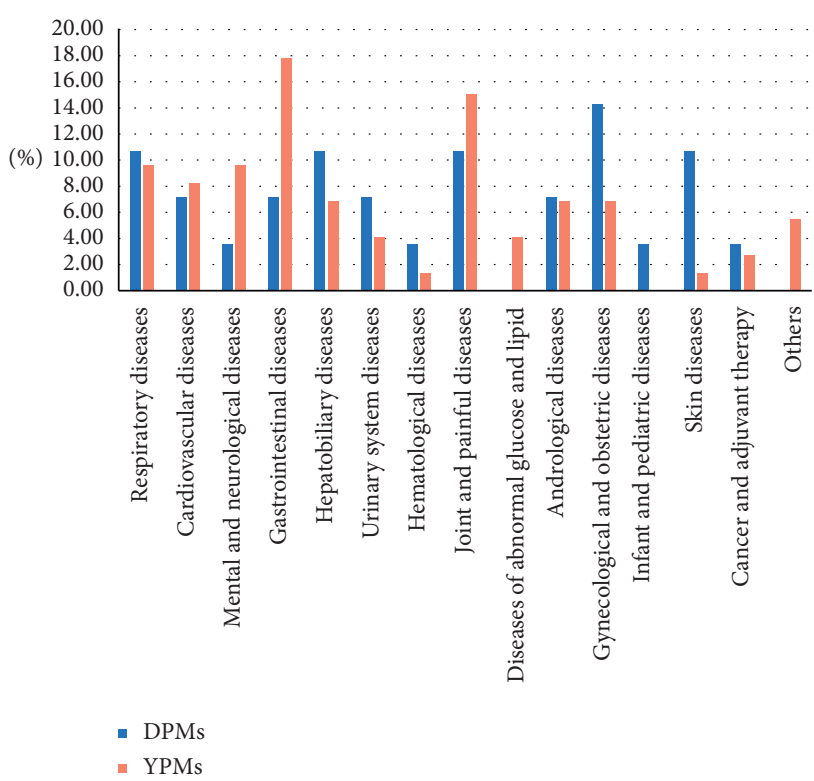

FIgure 1: Clinical indications of DPMs and YPMs. DPMs, Dai patent medicines; YPMs, Yi patent medicines.

quality of life of stroke patients with cerebral infarction [9]. DDTN is also found to prevent cerebral injury in rats with middle cerebral artery-induced ischemic stroke by decreasing the intracellular $\mathrm{Ca}^{2+}$ concentration and inhibiting the release of excitatory amino acids [10].

\section{Application of Quality Standards for Yi Medicine and Dai Medicine}

In China, the quality standards of ethnic medicines and their patent medicines are based on the national standards included in the Chinese Pharmacopoeia, which has covered ethnomedicines since 1977. Previous research on EPMs in the Chinese Pharmacopoeia (2015 edition) found that some traditional medicines did not establish national quality standards, and that 71 traditional medicines, which include 39 EPMs, are not listed in the Chinese Pharmacopoeia [11]. This practice (called "upside-down standards,") that involves quality standards for Chinese patent medicines (CPMs) but no standard for the composition of CPMs affects the safety of $\mathrm{CPMs}$ and the healthy development of the Chinese pharmaceutical industry. 
The provincial standards relating to the Tibetan, the Xinjiang Uygur, the Inner Mongolia, the Guangxi Zhuang Autonomous Region, Qinghai, Sichuan, and Yunnan and Guizhou provinces also apply to the regulation of the quality of ethnic medicines in China [12]. The academy group and enterprise standards are also applicable to the quality of ethnomedicine. The 28 DPMs identified in the survey include 101 traditional medicines with quality standards listed in the Chinese Pharmacopoeia (2015 edition). The quality standards of 30 traditional medicines are listed in the Standards for Chinese medicinal materials in Yunnan Province (SYNP) or other provincial quality standards (Figure 2). Four herbal medicines including Aristolochia chuii Wu (Dabaijie), Michelia mahan C. Y. Wu (Mahan), Asparagus officinalis L. (Xiaobaibu), and leaf and stem of Vitex trifolia L. do not have applicable quality standards or are out of date. The 73 YPMs identified in the survey included 182 traditional medicines with quality standards in the Chinese Pharmacopoeia (2015 edition). The quality standards of 88 traditional medicines are included in the SYNP or other provincial pharmacopoeias. Eleven herbal medicines have no applicable quality standards or are out of date, including the root of Rosa odorata (Andr.) Sweet var. gigantea (Crép.) Rhed. Et Wils. (Gugongguo), Fibraurea recisa Pierre (Dahuangteng), Dolichos falcata Klein (Damayao), Cyanotis arachnoidea G. B. Clarke (Lushuicao), Bulbophyllum reptans (Lindl.) Lindl. (Xiaolvji), Adenophora bulleyana Diels (Shashen), Cynoglossum officinale L. (Daotihu), Crepis lignea (Vant.) Babc. (Wanzhangsheng), Cymbopogon distans (Nees) Wats. (Yunxiangcao), and Ziheche and extract of Hemsleya chinensis Cogn. ex Forbes et Hemsl (Xuedan extract). More information is provided in Tables S3 and S4.

The usage frequencies of traditional medicines in DPMs and YPMs are shown in Figure 3. Glycyrrhiza uralensis Fisch (Gancao), Panax notoginseng (Burk.) F. H. Chen (Sanqi), Angelica sinensis (Oliv.) Diels (Danggui), Astragalus membranaceus (Fisch.) Bge. Var. mongholicus (Bge.) Hsiao, and Astragalus membranaceus (Fisch.) Bge. (Huangqi) are the most frequently used genuine medicinal materials in Yunnan Province. The other medicines included in the SYNP as Dai medicines or Yi medicines are listed in Table 2.

\section{Application of Medicinal Resources in Yi and Dai Medicine}

6.1. Botanical, Animal, and Mineral Sources of Medicines Used in DPMs and YPMs. Differences in geographical and climatic conditions are reflected in distinct lifestyle, customs, cultures, and usage of medicinal resources by the residents of the various regions in China. In general, botanicals are the most widely used traditional medicines. DPMs and YPMs include 361 botanical medicines, 22 animal source of medicines, and 9 mineral medicines, as shown in Figure 4. YPMs contain more animal sources of medicines than DPMs. Yi people have a long history of hunting, and many ancient documents attest to the use of animal sources of medicines. The Yi Nationality Offering Medicine Scriptures (Yi Zu Xian Yao Jing), written in the early Qing Dynasty,

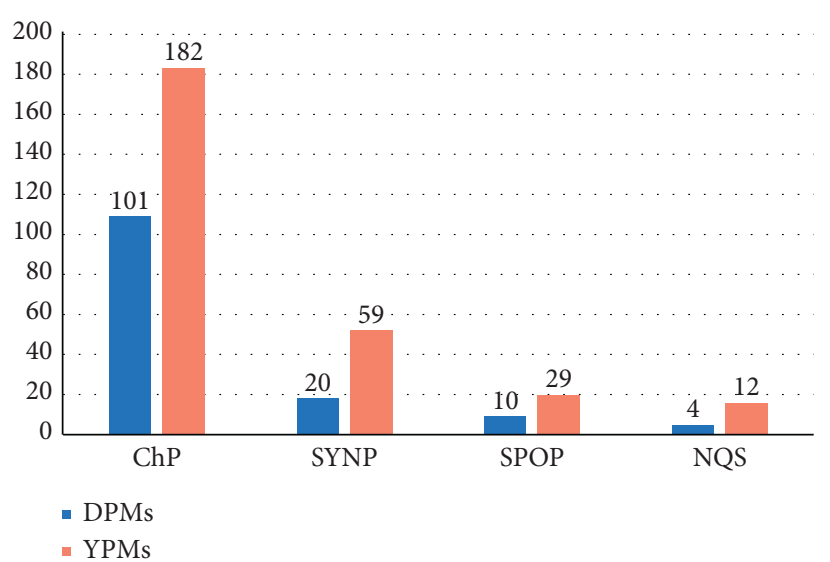

FIgure 2: Quality standards of herbal medicines in DPMs and YPMs. ChP, China Pharmacopoeia; SYNP, Standards for Chinese medicinal materials in Yunnan Province; SPOP, Standards for Chinese medicinal materials in other province except Yunnan; NQS, No quality standard.

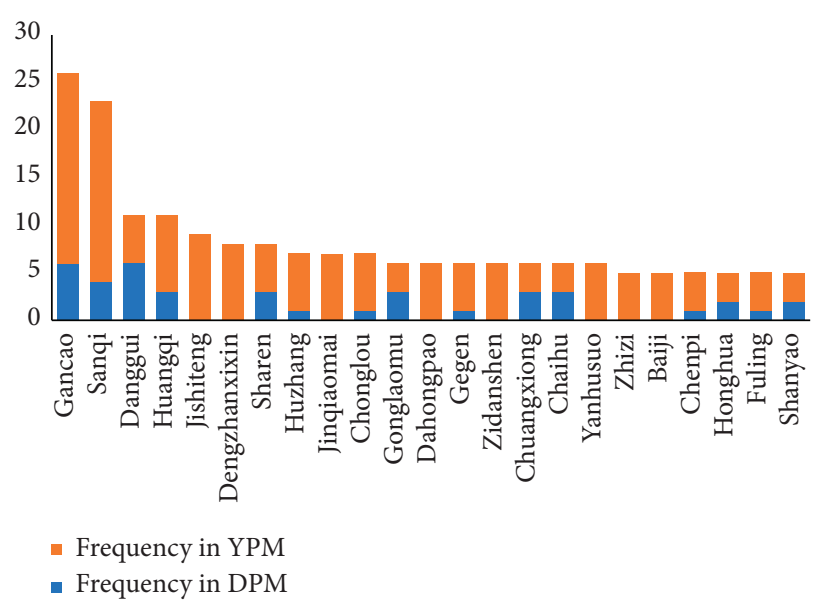

FIGURE 3: Usage frequencies of herbal medicines in DPMs and YPMs. DPM, Dai patent medicine; YPM, Yi patent medicine; Gancao, Glycyrrhiza glabra L. or Hemsleya chinensis Cogn.ex Forbes et Hemsl (Xuedan extract ; Sanqi, Panax notoginseng (Burk.) F. H. Chen; Danggui, Angelica sinensis (Oliv.) Diels; Huangqi, Astragalus propinquus Schischkin; Jishiteng, Paederia scandens (Lour.) Merr.; Dengzhanxixin, Erigeron breviscapus (Vaniot) Hand. -Mazz; Sharen, Amomum villosum Lour.; Huzhang, Polygonum cuspidatum Sieb.et Zucc.; Jinqiaomai, Fagopyrum dibotrys (D. Don) Hara; Chonglou, Paris polyphylla Smith var. chinenisi (Franch) Hara; Gonglaomu, Mahonia bealei (Fort.) Carr.; Dahongpao, Campylotropis hirtella (Franchet) Schindler; Gegen, Pueraria lobata (Willd.) Ohwi; Zidanshen, Salvia yunnanensis C. H. Wright; Chuangxiong, Ligusticum chuanxiong Hort.; Chaihu, Bupleurum scorzonerifolium Willd; Yanhusuo, Corydalis yanhusuo W. T. Wang; Zhizi, Gardenia jasminoides Ellis; Baiji, Bletilla striata (Thunb.) Reichb. f.; Chenpi, Citrus japonica Blanco; Honghua, Carthamus tinctorius $\mathrm{L}$.

notes that up to $92.8 \%$ of the prescriptions were animal sources of medicines and were divided into 12 types including insects, meat, bones, gallbladders, fat, blood, fish gall bladders, and hair. The Book of Good medicines for Treating 
TABLE 2: Traditional medicines used in DPMs and YPMs and listed in the SYNP.

\begin{tabular}{|c|c|c|c|c|c|}
\hline No & Scientific name & Pinyin name & MP & EM & Frequency \\
\hline 1 & Plumbago zeylanica Linn. & Baihuadan & Stem and leaf & Yi & 1 \\
\hline 2 & Toddalia asiatica (L.) Lam. & Feilongzhangxue & Stem & $\mathrm{Yi}$ & 1 \\
\hline 3 & Tripterygium hypoglaucum (Levl.) Hutch & Huobahuagen & Root & Yi & 3 \\
\hline 4 & Inula cappa (Buch -Ham) DC. & Yang'erju & Whole plant & $\mathrm{Yi}$ & 2 \\
\hline 5 & Geum aleppicum Thumb. var. Chinese Bolle & Wuqihuanyangcao & Whole plant & $\mathrm{Yi}$ & 3 \\
\hline 6 & Rhodobryum giganteum (Hook.) Par. & Huixincao & Whole plant & $\mathrm{Yi}$ & 2 \\
\hline 7 & Polygonum paleaceum Wall. ex Hook. & Caoxuejie & Rhizome & $\mathrm{Yi}$ & 2 \\
\hline 8 & Polygala arillata Buch. Ham. ex D. Dom & Jigen & Roots and rhizome & Yi & 1 \\
\hline 9 & Salvia yunnanensis C. H. Wright & Zi Danshen & Root & $\mathrm{Yi}$ & 6 \\
\hline 10 & Ampelopsis delavayana (Franch.) Planch. & Yuputao gen & Root & $\mathrm{Yi}$ & 3 \\
\hline 11 & Swertia patens Burk. & Xiao'er futong cao & Whole plant & $\mathrm{Yi}$ & 3 \\
\hline 12 & Polygonum cuspidatum Sieb.et Zucc. & Huzhangye & Leaf & Yi & 1 \\
\hline 13 & Cynodon dactylon (L.) Pers. & Qianxiancao & Whole plant & Yi & 1 \\
\hline 14 & Potentilla fulgens Wall. ex Hook & Guanzhong & Root & Yi & 2 \\
\hline 15 & Ainsliaea pertyoides Franch. var. albo-tomentosa Beauv. & Yexiahua & Whole plant & $\mathrm{Yi}$ & 1 \\
\hline 16 & Valeriana jatamansi Jones & Matixiang & Roots and rhizome & Yi & 1 \\
\hline 17 & Speranskia tuberculata (Bunge) Baillon & Tougucao & Aerial part & $\mathrm{Yi}$ & 3 \\
\hline 18 & Arthromeris mairei (Brause) Ching & Diwugong & Rhizome & Yi & 1 \\
\hline 19 & Schefflera venulosa (Wight et Arn.) Harms & Qiyelian & Whole plant, stem, and leaf & Yi & 3 \\
\hline 20 & Boenninghausenia sessilicarpa Levl. & Shijiaocao & Whole plant & Yi & 2 \\
\hline 21 & Oxalis corniculata Linn. & Zajiacao & Whole plant & Yi & 1 \\
\hline 22 & Anemone rivularis Buch. Ham. ex DC. & Huzhangcao & Root & Yi & 2 \\
\hline 23 & Opuntia stricta (Haw.) Haw. var. dillenii (Ker Gawl.) Benson. & Xianrencao & Stem & $\mathrm{Yi}$ & 1 \\
\hline 24 & Dysosma versipellis (Hance) M. Cheng ex Ying & Bajiaolian & Rhizome & Yi & 4 \\
\hline 25 & Jatropha curcas L. & Gaotong & Root bark, stem bark & Yi & 1 \\
\hline 26 & Ficus tikoua Bur. & Dibanteng & Cane & $\mathrm{Yi}$ & 1 \\
\hline 27 & Kadsura longipedunculata Finet et Gagnep. & Wuxiangxueteng & Cane & Yi & 3 \\
\hline 28 & Leycesteria aponic Wall. var. stenosepala Rehd. & Dazuifeng & Aerial part & $\mathrm{Yi}$ & 1 \\
\hline 29 & Anaphalis bulleyana (J. F. Jeffr.) Chang & Wuxiangcao & Whole plant & Yi & 1 \\
\hline 30 & Craibiodendron yunnanense W.W. Smith & Jinyezi & Leaf & Yi & 1 \\
\hline 31 & Phyllanthus urinaria L. & Yexiazhu & Aerial part & Dai & 2 \\
\hline 32 & Brassica integrifolia (West) O. E. Schulz ex Urb. & Kucaizi & Seed & Dai & 1 \\
\hline 33 & Zingiber purpureum Rosc. & Zisejiang & Rhizome & Dai & 1 \\
\hline 34 & Polyrhachis dives Smith & Weimayi & Body & Dai & 4 \\
\hline 35 & Phyllanthus niruri L. & Zhuzicao & Whole plant & Dai & 1 \\
\hline 36 & Tacca chantrieri Andre & Jiangenshu & Stem tuber & Dai & 2 \\
\hline 37 & Stephania epigaea H. S. Lo & Diburong & Root tuber & Dai & 1 \\
\hline 38 & Streptocaulon juventas (Lour.) Merr. & Tengkushen & Root & Dai & 1 \\
\hline 39 & Inula cappa (Buch.-Ham) DC & Yangerjugen & Root & Dai & 1 \\
\hline 40 & Benincasa hispida (Thunb.) Cogn. & Kudonggua & Fruit & Dai & 1 \\
\hline
\end{tabular}

DPMs, Dai patent medicines; YPMs, Yi patent medicines; SYNP, Standards for Chinese medicinal materials in Yunnan Province; MP, medicinal parts; EM, ethnic medicine.

Diseases (Yi Bing Hao Yao Shu, AD.1737) describes 152 animal sources of medicines that accounted for $35.7 \%$ of $\mathrm{Yi}$ medicines [13].

Animals are therapeutic arsenals with a significant role in healing. Zootherapy are derived from products of metabolism (e.g., corporal secretions and excrements) or from nonanimal materials such as nests or cocoons [14]. The reasonableness of zootherapy cannot be denied, and evidence supporting their use should be strengthened by modern scientific research. The animal sources of medicines in DPMs and YPMs are listed in Table 3. The use of some animal products in DPMs and YPMs is controversial, e.g., Cordyceps sinensis, Moschus deer musk, and bear bile, because these medicinal materials originate from protected wild animals or by harvesting activities that harm the ecological environment. Nevertheless, the production and

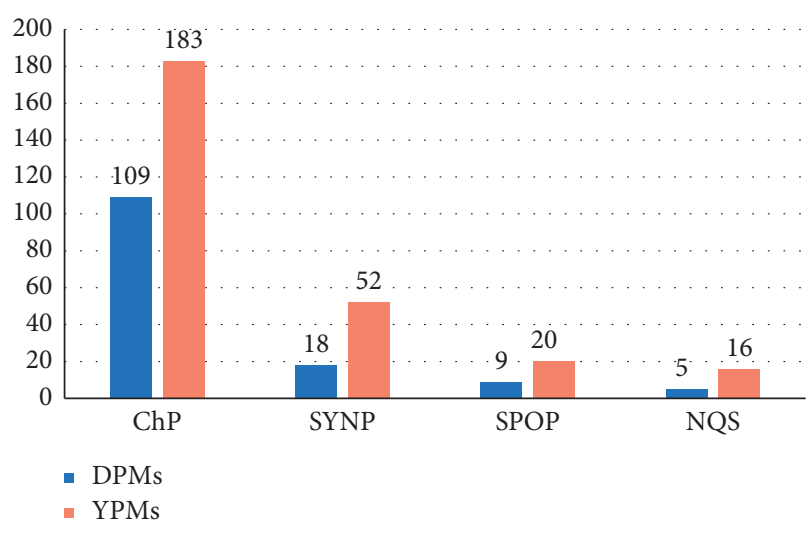

FIGURE 4: The use of botanical, animal, and mineral resources in DPMs and YPMs. DPMs, Dai patent medicines; YPMs, Yi patent medicines. 
TABLE 3: Medicinal sources from the animals used in DPMs and YPMs that are listed in the SYNP.

\begin{tabular}{|c|c|c|c|c|c|}
\hline Scientific name & Pinyin name & MP & Standard & DPM & YPM \\
\hline Cervus nip port Temminck & Lurong & Antler & $\mathrm{ChP}$ & 1 & 0 \\
\hline Cryptotympana pustulata Fabricius & Chantui & Slough & ChP & 2 & 0 \\
\hline Gallus gallus domesticus Brisson & Jineijing & Gizzard & ChP & 1 & 1 \\
\hline Polyrhachis dives Smith & Heimayi & Body & SYNP & 1 & 4 \\
\hline Gekko gecko Linnaeus & Gejie & Body & ChP & 0 & 4 \\
\hline Pheretima aspergillum (E. Perrier) & Dilong & Body & ChP & 0 & 4 \\
\hline Bufo bufo gargarizans Cantor & Chansu & Secretion & $\mathrm{ChP}$ & 0 & 1 \\
\hline Aspongopus chinensis Dallas & Jiuxiangchong & Body & ChP & 0 & 2 \\
\hline Selenarctos thibetanus Cuvier & Xiongdanfen & Bile & SYNP & 0 & 1 \\
\hline Bombyx mori Linnaeus & Jiangchan & Body & $\mathrm{ChP}$ & 0 & 1 \\
\hline Periplaneta japonica Linnaeus & Feilie & Body & SYNP & 0 & 1 \\
\hline Sepiella maindroni de Rochebrune & Haipiaoqiao & Shell & ChP & 0 & 1 \\
\hline Moschus berezovskii Flerov & Shexiang & Secretion & $\mathrm{ChP}$ & 0 & 1 \\
\hline Armadillidium vulgare Latreille & Shufuchong & Body & SSDP & 0 & 2 \\
\hline Cervus nip port Temminck & Lujiaoshuang & Antler colloid & $\mathrm{ChP}$ & 1 & 1 \\
\hline Cordyceps sinensis (BerK.) Sacc. & Dongchongxiacao & Bacterial and insect complex & $\mathrm{ChP}$ & 2 & 2 \\
\hline
\end{tabular}

EPM, ethnic patent medicine; MP, medicinal parts; ChP, Chinese Pharmacopoeia; SSDP, Standards for Chinese medicinal materials in Shandong Province (2012).

use of such animal sources of medicines are restricted in China. China has joined and complied with many conventions on biological protection such as CITES (Convention on International Trade in Endangered Species of Wild Fauna and Flora) and the Convention on Biological Diversity and has implemented domestic animal protection regulations. However, the medicinal value of these and other animal sources of medicines cannot be ignored. Fortunately, substitutes are available because of the cultivation of Cordyceps and industrial production of artificial musk $[15,16]$. Bile can be obtained from living, farmed bears but is ethically controversial [17]. Artificial bear bile has been reported to be effective on anticonvulsion, sedative, and choleretic [18].

6.2. Medicinal Parts of Botanical Medicines. Yunnan is rich in Chinese Materia medica resources and is known as the kingdom of plants. The plant parts used in herbal medicines include seeds, berries, roots, leaves, fruits, barks, and flowers and the whole plant itself. From ancient times to the present, people have used crude botanical materials as medicines to maintain vitality and cure disease [19]. The medicinal parts of botanical medicines in DPMs and YPMs are shown in Figure 5. The plant parts included in DPMs and YPMs are similar, with root and rhizomes, the whole plant, and fruit and seeds being the most frequent. The various parts of the medicinal plants contain active components that are responsible for their effectiveness [20] and physical properties that determine their names [21]. For example, Huangqin (Scutellaria baicalensis Georgi) is called "Rijishi" in the Yi language, in which "Ri" means herbaceous plant; "Ji" means root, the medicinal part of the plant; "Shi" indicates that the color is yellow [22]. The continuing usage of herbal medicines prepared from wild roots and rhizomes, fruits and seeds, and whole plants is not sustainable. The best strategy for balancing industrialization and resource protection is replacing wild with cultivated resources [23].

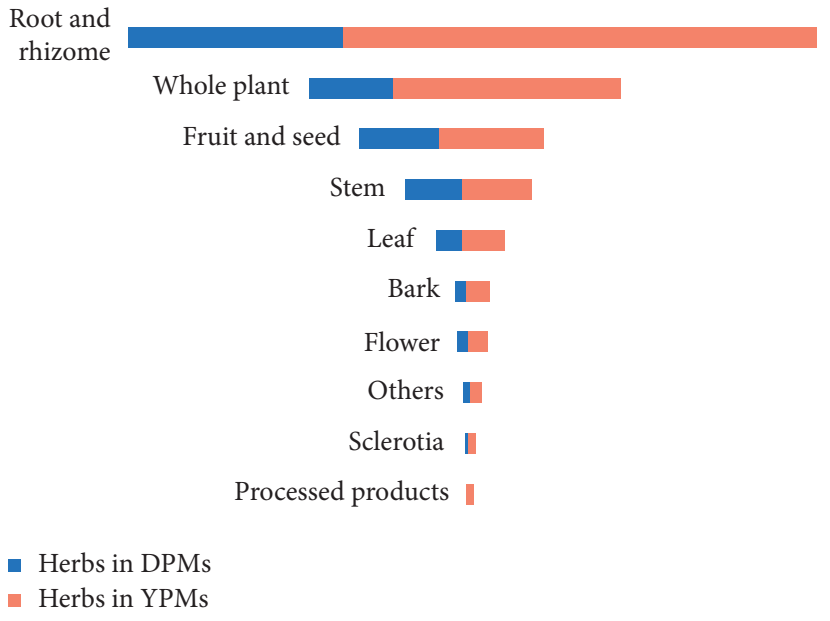

FIGURE 5: Relative contribution of the parts of medicinal plants to DPMs and YPMs.

\section{Rare and Endangered Medicinal Materials}

The rapidly increasing demand for CPMs is likely to challenge the sustainability of herbal resources in China. At present, $80 \%$ of the most frequently used species cannot meet medical demand, and 1,800-2,100 medicinal species are facing extinction [24]. In the China Plant Red Data Book published in 1992, 388 plant species were listed as threatened, with 121 species as endangered and needing first-grade national protection, 110 species as rare needing secondgrade national protection, and 157 species as vulnerable needing third-grade national protection. Of those plant species, 77 are herbal medicines that account for $19.86 \%$ of the threatened species [25]. The national key protection name list of wild animals in China includes 257 animal sources. The shortage of medicinal plants available to pharmaceutical companies can be partially reduced by the cultivation of at least 200 herbs, while some special herbs 
used in ethnomedicine are obtained by continuous wild collection without planned scientific cultivation. The rare medicinal materials used in DPMs and YPMs are listed in Table 4 .

Those plants are protected by the Chinese government and some international nongovernment organizations such as the International Union for Conservation of Nature. Cistanche deserticola Y. C. Ma (Rouchongrong), Panax ginseng C. A. Mey (Renshen), Glycyrrhiza aponic Bat (Gancao), or other rare medicinal materials listed in the catalogs is protected and utilized sustainably in China. However, the number of endangered ethnic-specific medicines is far larger than that recorded in the catalogs; for example, more than 3000 tons of Rodgersia sambucifolia Hemsl. (Yantuo) are collected annually to produce YPMs. The availability of wild Rodgersia plants is sharply reduced, and resources are severely damaged in Luquan, Yongsheng, Yulong, Heqing, and Ninglang counties of Yunnan Province [26], while its cultivation research just began in recent years. Figure 6 shows the planting situation of Rodgersia sambucifolia Hemsl. in the Meizi test ground, which is subordinate to the Institute of Alpine Economics and Botany, Yunnan Academy of Agricultural Sciences. Consequently, 30 traditional medicines have been listed in the Rare Traditional Chinese Herbs of Yunnan Province in Urgent Needs (RTCHYN), and those used in DPMs and YPMs are shown in Table 5 [27].

Medicines with pharmacological activities that are present in traditional ethnomedicine are likely to be clinically useful, but they may also be toxic, especially if used incorrectly or in the wrong amounts. Unlike that for modern drugs, the efficacy and toxicity assessments of these ethnomedicines are based on traditional knowledge and clinical experience rather than on laboratory evaluation [28]. Toxicity associated with the use of Chinese ethnomedicine may occur because of the environment, religious beliefs, or medical practices. The Chinese Pharmacopoeia includes 83 traditional medicines that are considered toxic [29]; some medicines listed in provincial standards of herbal medicines are also considered toxic [30].

Ten toxic medicines are used in 11 DPMs; six of those are included in the Chinese Pharmacopoeia (2015 edition) and four toxic medicines in the SYNP. One toxic medicine is used in Dai traditional medicine, and two toxic medicines are used in Yi traditional medicine. The 40 YPMs include 24 toxic herbs; 12 toxic medicines are in the Chinese Pharmacopoeia (2015 Edition) and 12 are in the SYNP. Four medicines are known as Yi medicines. Although some toxic ethnomedicines are used in DPMs and YPMs, the proprietary medicines are considered safe and approved for use in China because pharmaceutical processing, combining, and decocting contribute to reducing toxicity and enhancing efficacy. In the traditional Dai medicine (TDM), "YaGei" herbs are used to reduce toxicity. The "YaGei" detoxification theory is a unique supplement of TDM [31], and "YaGei" medicines are used as antidotes to relieve adverse reactions caused by food poisoning, drug poisoning, and other substances [32]. Dai people consume antidotes regularly to eliminate the microtoxins from the body, reduce the chance of illness, and prolong life.
Due to the lack of more pharmaceutical information disclosed, as well as the lack of basic research, the safety information of these DPMs and YPMs including toxic medicines is insufficient. The modern toxicological evidence of these toxic medicines is collected and summarized in Tables 6 and 7, focusing on Dai and Yi toxic medicines. The root of Tripterygium hypoglaucum (Levl.) Hutch (Huobahuagen) soaked in wine as an oral medicine is an ancient Yi medicine described in the Ailao Materia Medica in the treatment of arthritis, joint swelling, pain, bruises, and sprains [59]. Boenning hauseniase silicarpa Levl. (Shijiaocao) is described in the Materia Medica in South Yunnan (Dian Nan Ben Cao, AD.1396 -1476) written by Lan Mao as a bitter, pungent, and warm medicine used to treat chest pain, heartache, stomachache, and abdominal distension. Shijiaocao is also described in the Ailao Materia Medica as a treatment for sore throat, gastric pain, and dysentery. It is described as a cure of acute gastroenteritis in combination with the parasite of Zanthoxylum bungeanum in the Wa Die Yi Medical Book, which was written at the end of the Qing Dynasty [60]. Ancient documents describe the usage of the toxic herbs included in the medical practice of $\mathrm{Yi}$, Dai, or other ethnic minorities in Yunnan. Modern toxicological study can ensure their safe and effective use, and further study is warranted to determine how the toxicity reduces while the prescription remains effective.

\section{Concluding Remarks}

Ethnomedicine is an important part of TCM that has a unique medical theoretical system and refers to a wide range of healthcare systems/structures, practices, beliefs, and therapeutic techniques that arise from indigenous cultural development. Thousands of years of ethnic amalgamation has produced diversity, integration, and differences among the traditional medicine of different Chinese ethnics. Approximately 8,000 medicinal species are used by 40 ethnic minorities in China, which account for over $70 \%$ of the Chinese Materia medica resources. Data from the National Medical Products Administration of China show that there are more than 600 types of EPMs [12]. The Chinese Pharmacopoeia (1977 edition) began to cover DPMs, and some Miao patent medicines and YPMs were collected from the 2015 edition of Chinese Pharmacopoeia. Overall, a total of 39 CPMs were identified as EPMs, 26 EPMs as prescription drugs, and 13 EPMs as OTC drugs [11]. Prescriptions that are not approved by the government were not included in the review evaluated, but are still in use in clinics in regions of China inhabited by ethnic groups.

This review focuses on Dai and Yi traditional medicines in Yunnan Province because of their long histories and descriptions in the ancient medical literature. The earliest book of Yi traditional medicine that can be verified is the Yuanyang Yi Medicine Book, which was written in $957 \mathrm{AD}$ and found in Yuanyang County of Yunnan Province in 1985 [14]. The earliest books of Dai traditional medicine that can be verified are $\mathrm{Ge} \mathrm{Ya} \mathrm{San} \mathrm{Ha} Y a$, which was written in 964$884 \mathrm{BC}$, and Dang Ha Ya Long, which was written in 1323 $\mathrm{AD}$ [61]. There are 1, 666 Dai medicines [62], nearly 1, $400 \mathrm{Yi}$ 
TABLE 4: Rare medicinal materials used in DPMs and YPMs.

\begin{tabular}{|c|c|c|c|c|c|c|}
\hline Herbal name & Scientific name & NPWP & IUCN & Proprietary & NPWM & UF \\
\hline \multirow{3}{*}{ Gancao } & Glycyrrhiza uralensis Fisch & II & LC & - & II & \\
\hline & Glycyrrhiza inflata Bat. & II & LC & - & II & 26 \\
\hline & Glycyrrhiza glabra L. & II & $\mathrm{LC}$ & - & II & \\
\hline Renshen & Panax ginseng C. A. Mey & I & CR & - & II & 4 \\
\hline Lianqiao & Forsythia suspense (Thunb.) Vahl. & - & - & - & III & 4 \\
\hline Huangqin & Scutellaria baicalensis Georgi & - & - & - & III & 4 \\
\hline Wuweizi & Schisandra chinensis (Turcz.) Baill. & II & LC & - & III & 1 \\
\hline \multirow{2}{*}{ Lurong } & Cervus nip port Temminck & - & - & - & $\mathrm{I}$ & \\
\hline & Cervus elaphus Linnaeus & - & - & - & I & t \\
\hline \multirow{2}{*}{ Rouchongrong } & Cistanche deserticola Y. C. Ma & II & $\mathrm{EN}$ & - & III & \\
\hline & Cistanche tubulosa (Schenk) Wight & II & - & - & - & 1 \\
\hline Huangbai & Phellodendron chinense Schneid & - & - & - & II & 2 \\
\hline Duzhong & Eucommia ulmoides Oliv. & - & - & - & II & 1 \\
\hline \multirow{4}{*}{ Longdan } & Gentiana manshurica Kitag. & - & - & - & III & \\
\hline & Gentiana scabra Bge & - & - & - & III & \\
\hline & Gentiana triflora Pall. & - & - & - & III & 3 \\
\hline & Gentiana regescens Franch. & - & - & - & III & \\
\hline \multirow{3}{*}{ Huanglian } & Coptis chinensis Franch & - & - & Unique to China & II & \\
\hline & Coptis deltoidea C. Y. Cheng et Hsiao & - & VU & Unique to China & II & 1 \\
\hline & Coptis teetoides C. Y. Cheng. & - & - & $1-$ & II & \\
\hline \multirow{2}{*}{ Houpu } & Magnolia officinalis Rehd. et Wils & II & NT & Unique to China & II & \\
\hline & Magnolia officinalis Rehd. et Wils. var. biloba Rehd. et Wils & II & - & Unique to China & II & 1 \\
\hline Huangbai & Phellodendron chinense Schneid & - & - & - & II & 2 \\
\hline Zicao & Arnebia euchroma (Royle) Johnst & - & - & - & III & 1 \\
\hline \multirow{4}{*}{ Qingjiao } & Gentiana macrophylla Pall. & - & - & - & III & \\
\hline & Gentiana macrophylla Maxim. & - & - & - & III & 1 \\
\hline & Gentiana crassicaulis Duthie ex Burk. & - & - & - & III & 1 \\
\hline & Gentiana dahurica Fisch & - & - & - & III & \\
\hline \multirow{3}{*}{ Shexiang } & Moschus berezovskii Flerov. & - & - & - & II & \\
\hline & Moschus sifanicus Przewalski. & - & - & - & II & 1 \\
\hline & Moschus moschiferus Linnaeus. & - & - & - & II & \\
\hline Chonglou & Paris polyphylla Smith var. chinensis (Franch.) Hara & II & - & - & - & 7 \\
\hline
\end{tabular}

NPWP, National Key Protected Wild Plants of China (August 4, 1999); NPWM, National Key Protected Species of Wild Medicinal Materials of China (Dec. 1, 1987); IUCN, International Union for Conservation of Nature (CR, critically endangered; LC, least concern; EN, endangered; VU, vulnerable; NT, near threatened); UF, usage frequency in DPMs and YPMs.

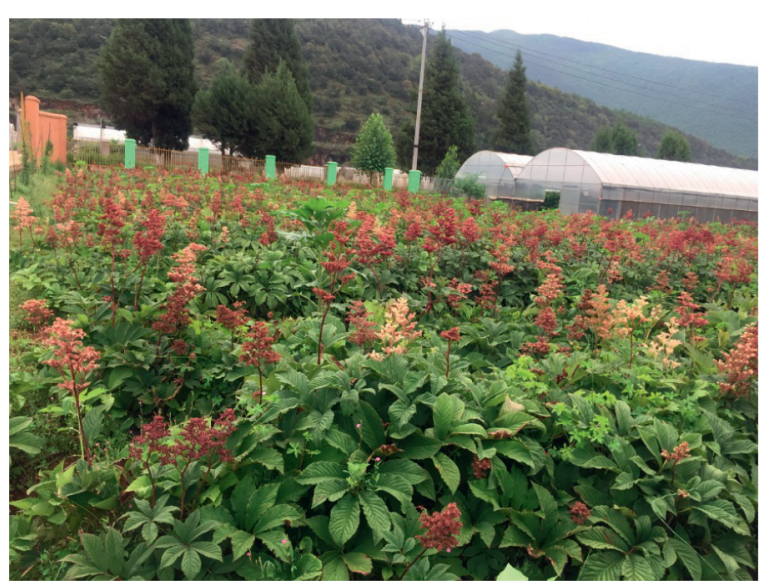

(a)

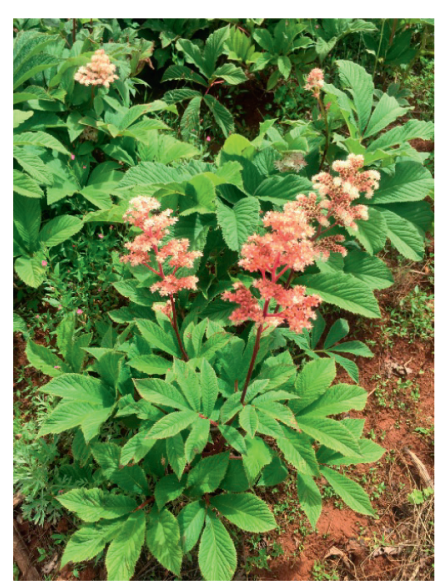

(b)

FIgUre 6: Rodgersia sambucifolia Hemsl. cultivated in the Meizi test ground (Lijiang, Yunnan). Toxic medicines used in DPMs and YPMs.

medicines [13], and 400 medicines are listed in the $Y i$ Materia Medica [63]. There are 478 Yi medical formulas described in Chinese Yi Medicine Prescriptions Science [64], and 200 Dai medical formulas are in Study on Dai classical prescriptions of China [65]. The numbers of folk formulas from Dai and Yi traditional medicine are not available to record yet. Just as the example of Yunnan Baiyao mentioned before, a series of ethnomedicines in Yunnan were 
TABLE 5: Traditional medicines listed in the RTCHYN.

\begin{tabular}{|c|c|c|c|c|c|}
\hline Scientific name & Pinyin name & Medicinal parts & Regional distribution* & Standard & UF \\
\hline $\begin{array}{l}\text { Erigeron breviscapus (Vaniot) Hand. } \\
\text {-Mazz. }\end{array}$ & Dengzhanxixin & Whole plant & Areas except southwest of Yunnan & $\mathrm{ChP}$ & 7 \\
\hline Cordyceps sinensis (BerK.) Sacc. & Dongchongxiacao & $\begin{array}{l}\text { Bacterial and } \\
\text { insect complex }\end{array}$ & $\begin{array}{l}\text { Deqin, Shangri-La, Lijiang, Binchuan, } \\
\text { Lvfeng, Guangtong }\end{array}$ & $\mathrm{ChP}$ & 4 \\
\hline $\begin{array}{l}\text { Dracaena cochinchinensis (Lour.) S. C. } \\
\text { Chen A }\end{array}$ & Longxuejie & Resin & $\begin{array}{c}\text { Jinping, Menglian, Pu’er, Jinghong, } \\
\text { Zhenkang }\end{array}$ & SGZP & 2 \\
\hline Cyanotis arachnoidea C. B. Clarke & Lushuicao & Whole plant & $\begin{array}{c}\text { Menghai, Menglian, Jinghong, } \\
\text { Jingdong, Mengzi, Anning, Kunming, } \\
\text { Pingbian }\end{array}$ & No & 1 \\
\hline Swertia mileensis T. N. He et W. L. Shi & Qingyedan & Whole plant & Mile & $\mathrm{ChP}$ & 2 \\
\hline $\begin{array}{l}\text { Anisodus acutangulus C. Y. Wu et C. } \\
\text { Chen }\end{array}$ & Sanfensan & Roots & Lijiang & SYNP & 1 \\
\hline Hemsleya amabilis Diels & Xuedan & Roots & $\begin{array}{l}\text { Kunming, chongming, Binchuan, } \\
\text { Eryuan, Dali, Heqing }\end{array}$ & No & 1 \\
\hline $\begin{array}{l}\text { Bergenia purpurascens (Hook.f.et } \\
\text { Thoms.) Engl. var. delavayi (Franch.) } \\
\text { Engl. et Irm. }\end{array}$ & Yanbaicai & Rhizome & $\begin{array}{c}\text { Deqin, Weixi, Shangri-La, Lijiang, Dali, } \\
\text { Qujing, Ludian, Zhaotong, Gongshan, } \\
\text { Fugong }\end{array}$ & $\mathrm{ChP}$ & 1 \\
\hline
\end{tabular}

RTCHYN, Rare Traditional Chinese Herbs of Yunnan Province in Urgent Needs. ${ }^{*}$ Regional distribution is from the Flora of Yunnan (Science Press of China, 2006). UF, usage frequency; ChP, Chinese Pharmacopoeia; SGZP, Standards for Chinese medicinal materials in Guizhou Province (2009); SYNP, Standards for Chinese medicinal materials in Yunnan Province (2005).

TABLE 6: Toxic medicines in DPMs.

\begin{tabular}{|c|c|c|c|c|c|c|}
\hline Scientific name & Pinyin name & $\begin{array}{c}\text { Toxicity } \\
\text { degree }\end{array}$ & Standard & DPM & Modern toxicology & References \\
\hline $\begin{array}{l}\text { Paris polyphylla Smith } \\
\text { var. chinensis (Franch) } \\
\text { Hara }\end{array}$ & Chonglou & LT & $\mathrm{ChP}$ & RBQC & $\begin{array}{l}\text { Toxic to the digestive system and has cardio } \\
\text { toxicity and neurotoxicity, } \mathrm{LD}_{50}=2.68 \mathrm{~g} / \mathrm{kg} \\
\text { (mice, p.o.) }\end{array}$ & {$[33]$} \\
\hline $\begin{array}{l}\text { Curculigo orchioides } \\
\text { Gaertn. }\end{array}$ & Xianmao & MT & ChP & LXBST & $\begin{array}{c}\mathrm{LD}_{50}=215.9 \mathrm{~g} / \mathrm{kg} \text { (ethanol extract, rats, p.o.) and } \\
\text { damages the liver, kidney, and reproductive } \\
\text { organs with oral administration of } 120 \mathrm{~g} / \mathrm{kg} \\
\text { (ethanol extract, rats, } 6 \text { months) }\end{array}$ & {$[34]$} \\
\hline $\begin{array}{l}\text { Cnidium monnieri (L.) } \\
\text { Cuss. }\end{array}$ & Shechuangzi & $\mathrm{LT}$ & $\mathrm{ChP}$ & LXBST & $\begin{array}{l}\text { Nausea and vomiting, decreased spontaneous } \\
\text { activity, shortness of breath, unstable gait, and } \\
\text { tremor (ethanol extract), } \mathrm{LD}_{50}=17.45 \mathrm{~g} / \mathrm{kg} \text { (mice, } \\
\text { p.o.), MTD }=1.50 \mathrm{~g} / \mathrm{kg} \text {, or } \mathrm{LD}_{50}=3.45 \mathrm{~g} / \mathrm{kg} \\
\text { (osthol, mice, p.o.) }\end{array}$ & {$[35-37]$} \\
\hline $\begin{array}{l}\text { Zanthoxylum nitidum } \\
\text { (Roxb.) DC. }\end{array}$ & Liangmianzhen & LT & $\mathrm{ChP}$ & $\begin{array}{c}7- \\
\text { JDHXO }\end{array}$ & $\begin{array}{l}\text { Nitidine chloride damages the liver and kidney } \\
\text { cells and decreases the heart rate of zebrafish }\end{array}$ & {$[38]$} \\
\hline $\begin{array}{l}\text { Pinellia ternate } \\
\text { (Thunb.) Breit. }\end{array}$ & Banxia & MT & ChP & SBZKG & $\begin{array}{l}\mathrm{LD}_{50}=42.7 \pm 1.27 \mathrm{~g} / \mathrm{kg} \text { (mice, p.o.), damages the } \\
\text { renal and liver, causes serious damage to gastric } \\
\text { mucosa, and has significant toxicity on pregnancy } \\
\text { maternal mice and embryo (total alkaloids) }\end{array}$ & {$[39]$} \\
\hline $\begin{array}{l}\text { Prunus armeniaca L. } \\
\text { var. ansu Maxim }\end{array}$ & Kuxinren & LT & $\mathrm{ChP}$ & SBZKG & $\begin{array}{l}\mathrm{LD}_{50} \text { of amygdalin is } 25 \mathrm{~g} / \mathrm{kg} \text { (mice, i.v.), } 887 \mathrm{mg} / \\
\mathrm{kg} \text { (mice, p.o.) and hydrocyanic acid produced by } \\
\text { amygdalin inhibits the activity of cytochrome } \\
\text { oxidase, leading to cell respiration inhibition and } \\
\text { cell death }\end{array}$ & {$[40]$} \\
\hline $\begin{array}{l}\text { Plumbago zeylanica } \\
\text { Linn. }\end{array}$ & Bhuadan & LT & SYNP & DLBSC & $\begin{array}{c}\text { Skin redness, swelling, and peeling when } \\
\text { contacted and antiovulation activities for female } \\
\text { rats (alcohol extract) }\end{array}$ & {$[41,42]$} \\
\hline Tacca chantrieri Andre & Jiangenshu & MT & SYNP & YGT & $\begin{array}{l}\text { Diarrhea and vomiting in mild intoxication and } \\
\text { intestinal mucosal exfoliation and hemorrhoea } \\
\text { appear in severe poisoning patients }\end{array}$ & {$[43]$} \\
\hline $\begin{array}{l}\text { Tripterygium } \\
\text { hypoglaucum (Levl.) } \\
\text { Hutch }\end{array}$ & Huobahuagen & $\mathrm{LT}$ & SYNP & GTSL & $\begin{array}{c}\mathrm{LD}_{50}=79 \mathrm{~g} / \mathrm{kg} \text { (male mice, p.o.), } \mathrm{LD}_{50}=100 \mathrm{~g} / \mathrm{kg} \\
(\text { female mice, p.o.), and reversible antifertility } \\
\text { effect }\end{array}$ & {$[44,45]$} \\
\hline $\begin{array}{l}\text { Erythrina variegata } \mathrm{L} \text {. } \\
\text { var. orientalis (L.) Merr }\end{array}$ & Haitongpi & MT & SSCP & GTSL & Unknown & \\
\hline
\end{tabular}

HT, high toxicity; MT, medium toxicity; LT, low toxicity; SSCP, Standards for Chinese medicinal materials in Sichuan Province (2010); SYNP, Standards for Chinese medicinal materials in Yunnan Province (2005); RBQC, Ru Bi Qing Capsule; LXBST, Lu Xian Bu Shen Tablet; 7-JDHXO, 7-Jie Du Huo Xue Ointment; SBZKG, Shen Bei Zhi Ke Granular; DLBSC, Dan Lv Bu Shen Capsule; YGT, YaGei Tablet; GTSL, Guan Tong Shu Oral liquid. 
TABLE 7: Toxic medicines in YPMs.

\begin{tabular}{|c|c|c|c|c|c|c|}
\hline Scientific name & Pinyin name & $\begin{array}{c}\text { Toxicity } \\
\text { degree }\end{array}$ & Standard & YPM & Modern toxicology & References \\
\hline $\begin{array}{l}\text { Paris polyphylla Smith var. } \\
\text { chinensis (Franch) Hara }\end{array}$ & Chonglou & LT & $\mathrm{ChP}$ & $\begin{array}{l}\text { GFNC, NQSG, } \\
\text { SYA, TSC, } \\
\text { ZTL }\end{array}$ & - & - \\
\hline Osmunda japonica Thunb. & Ziqiguanzhong & $\mathrm{LT}$ & $\mathrm{ChP}$ & SWYA & Unknown & - \\
\hline $\begin{array}{l}\text { Evodia rutaecarpa (Juss.) } \\
\text { Benth. }\end{array}$ & Wuzhuyu & LT & ChP & $\begin{array}{l}\text { GDQC, } \\
\text { HWYP }\end{array}$ & $\begin{array}{l}\mathrm{LD}_{50} \text { is } 2.70 \mathrm{~mL} / \mathrm{kg} \text { (volatile oil, } \\
\text { mice, p.o.), one of the main target } \\
\text { organ is the liver }\end{array}$ & {$[46]$} \\
\hline $\begin{array}{l}\text { Bufo bufo gargarizans } \\
\text { cantor }\end{array}$ & Chansu & MT & $\mathrm{ChP}$ & CLTC & $\begin{array}{l}\text { Ventricular arrhythmias and } \\
\text { increasing the levels of } \mathrm{Ca}^{2+}, \mathrm{CK} \text {, } \\
\text { and } \mathrm{LDH} \text { in the heart }\end{array}$ & {$[47]$} \\
\hline $\begin{array}{l}\text { Artemisia argyi Levl. Et } \\
\text { Vant. }\end{array}$ & Aiye & LT & ChP & KSG & $\begin{array}{c}\mathrm{LD}_{50} \text { is } 80.2 \mathrm{~g} / \mathrm{kg} \text { (aqueous extract, } \\
\text { mice, p.o.), } \mathrm{LD}_{50} \text { is } 1.67 \mathrm{~mL} / \mathrm{kg} \\
\text { (volatile oil, mice, p.o.), MTD is } \\
75.6 \mathrm{~g} / \mathrm{kg} \text { (ethanol extract, mice, } \\
\text { p.o.) }\end{array}$ & {$[48]$} \\
\hline $\begin{array}{l}\text { Aconitum kusnezoffii } \\
\text { Reichb. }\end{array}$ & Caowu & HT & $\mathrm{ChP}$ & TXT & $\begin{array}{l}\text { Causing serious cardiac dysfunction } \\
\text { and damaging the nervous system. } \\
\mathrm{LD}_{50} \text { is } 1.8 \mathrm{mg} / \mathrm{kg} \text {, (aconitine, mice, } \\
\text { p.o.), } \mathrm{LD}_{50} \text { is } 5.8 \mathrm{mg} / \mathrm{kg} \\
\text { (hypaconitine, mice, p.o.), and } \mathrm{LD}_{50} \\
\text { is } 1.9 \mathrm{mg} / \mathrm{kg} \text { (mesaconitine, mice, } \\
\text { p.o.). }\end{array}$ & {$[49,50]$} \\
\hline Papaver somniferum L. & Yingsuqiao & MT & ChP & KLT & $\begin{array}{l}\text { Main toxic components are } \\
\text { morphine and codeine. Morphine } \\
\text { with } 60 \mathrm{mg} \text { causes poisoning and } \\
250 \mathrm{mg} \text { leads to death }\end{array}$ & {$[51]$} \\
\hline $\begin{array}{l}\text { Arisaema erubescens (Wall.) } \\
\text { Schott. }\end{array}$ & Tiannanxing & MT & ChP & TXT & $\begin{array}{l}\text { Producing folate deficiency and } \\
\text { injury to the kidneys }\end{array}$ & {$[52]$} \\
\hline $\begin{array}{l}\text { Laggera pterodonta (DC.) } \\
\text { Benth. }\end{array}$ & Choulingdan & MT & $\mathrm{ChP}$ & LL, SKCG & $\begin{array}{c}\mathrm{LD}_{50} \text { is } 1.19 \mathrm{~g} / \mathrm{kg} \text { (water extract, } \\
\text { mice, i.p.) }\end{array}$ & [53] \\
\hline $\begin{array}{l}\text { Prunus armeniaca L. var. } \\
\text { ansu Maxim }\end{array}$ & Kuxinren & $\mathrm{LT}$ & $\mathrm{ChP}$ & SKCG, CLTC & - & - \\
\hline $\begin{array}{l}\text { Pinellia ternate (Thunb.) } \\
\text { Breit }\end{array}$ & Banxia & MT & $\mathrm{ChP}$ & $\begin{array}{l}\text { WFSC, } \\
\text { ZXASG }\end{array}$ & - & - \\
\hline $\begin{array}{l}\text { Psammosilene tunicoides } \mathrm{W} \text {. } \\
\text { C. Wu et C. Y. Wu }\end{array}$ & Jintiesuo & LT & ChP & ZTL & $\begin{array}{l}\mathrm{LD}_{50} \text { is } 4.8471 \text { (mice, p.o.) and toxic } \\
\text { target organs include the lungs, } \\
\text { spleen, and stomach }\end{array}$ & {$[54]$} \\
\hline $\begin{array}{l}\text { Boenninghausenia } \\
\text { sessilicarpa Levl. }\end{array}$ & Shijiaocao & LT & SYNP & SAC, SKCG & $\begin{array}{l}\text { The ether extract reduces the activity } \\
\text { in mice by intraperitoneal injection }\end{array}$ & {$[33]$} \\
\hline $\begin{array}{l}\text { Dysosma versipellis (Hance) } \\
\text { M. Cheng ex Ying }\end{array}$ & Bajiaolian & $\mathrm{LT}$ & SYNP & $\begin{array}{l}\text { ZTL, HJXJC, } \\
\text { SLAC, } \\
\text { WJHXZTT }\end{array}$ & $\begin{array}{l}\mathrm{LD}_{50} \text { is } 0.493 \pm 0.032 \mathrm{~g} / \mathrm{kg} \text { (mice, } \\
\text { p.o.) and is toxic to the heart and } \\
\text { central nervous system, appearing } \\
\text { excited then inhibited }\end{array}$ & {$[55]$} \\
\hline Millettia bonatiana Pamp. & Dafahan & MT & SYNP & HSTT & Damages the stomach & {$[33]$} \\
\hline $\begin{array}{l}\text { Craibiodendron yunnanense } \\
\text { W. W. Smith }\end{array}$ & Jinyezi & HT & SYNP & ZTL & Unknown & \\
\hline $\begin{array}{l}\text { Tripterygium hypoglaucum } \\
\text { (Levl.) Hutch }\end{array}$ & Huobahuagen & MT & SYNP & ZTL, GFNC & - & \\
\hline $\begin{array}{l}\text { Anemone rivularis Bunch. } \\
\text { Ham. ex DC. }\end{array}$ & Wuzhangcao & $\mathrm{LT}$ & SYNP & TYGT, YSL & Unknown & \\
\hline $\begin{array}{l}\text { Delphinium yunnanense } \\
\text { Franch. }\end{array}$ & Daotihu & MT & SGZP & WHXZTC & Unknown & \\
\hline Dioscorea bulbifera L. & Huangyaozi & LT & SGDP & FFLC, FFLG & $\begin{array}{l}\mathrm{LD}_{50} \text { is } 25.49 \mathrm{~g} / \mathrm{kg} \text { (mice, i.p.), } \mathrm{LD}_{50} \\
\text { is } 79.98 \mathrm{~g} / \mathrm{kg}, 250.3 \mathrm{~g} / \mathrm{kg} \text {, or } 544 \mathrm{~g} / \mathrm{kg} \\
\text { (mice, p.o.), toxic target organs } \\
\text { including the liver and kidney }\end{array}$ & {$[56,57]$} \\
\hline $\begin{array}{l}\text { Clematis apiifolia var. } \\
\text { argentilucida (H. Leveille \& } \\
\text { Vaniot) W. T. Wang }\end{array}$ & Shanmutong & LT & SHNP & NQSG & Unknown & \\
\hline
\end{tabular}


TABLE 7: Continued.

\begin{tabular}{|c|c|c|c|c|c|c|}
\hline Scientific name & Pinyin name & $\begin{array}{c}\text { Toxicity } \\
\text { degree }\end{array}$ & Standard & YPM & Modern toxicology & References \\
\hline $\begin{array}{l}\text { Anisodus acutangulus C. Y. } \\
\mathrm{Wu} \text { et } \mathrm{C} \text {. Chen }\end{array}$ & Sanfensan & HT & SYNP & TXT & Unknown & \\
\hline Datura stramonium L. & Mantuoluoye & MT & SYNP & YWNC & $\begin{array}{c}\text { Shortness of breath and death after } \\
\text { nerve stimulation }\end{array}$ & {$[33]$} \\
\hline $\begin{array}{l}\text { Aconitum brachypodum } \\
\text { Diels. }\end{array}$ & Xueshangyizhihao & HT & SHNP & ZTL & $\begin{array}{c}\mathrm{LD}_{50} \text { are } 6766.928 \text { and } 5492.337 \mathrm{mg} / \\
\mathrm{kg} \text { (petroleum ether extracts, } \mathrm{N}- \\
\text { butanol extracts, mice, p.o.) }\end{array}$ & {$[58]$} \\
\hline
\end{tabular}

HT, high toxicity; MT, medium toxicity; LT, low toxicity. ${ }^{*}$ The herb has more than two origins of species, only one origin is shown. SGZP, Standards for Chinese medicinal materials in Guizhou Province (2009); SGDP, Standards for Chinese medicinal materials in Guangdong Province (2011); SHNP, Standards for Chinese medicinal materials in Hunan Province (2009); SYNP, Standards for Chinese medicinal materials in Yunnan Province (2005). GFNC, Gu Feng Ning Capsule; NQSG, Niao Qing Shu Granular; SYA, Shang Yi Aerosol; TSC, Tong Shu Capsule; ZTL, Zhong Tong Liniment; SWYA, Shu Wei Yao Alcohol; GDQC, Gan Dan Qing Capsule; HWYP, Huoxiang Wan Ying Powder; CLTC, Chuan Luo Tong Capsule; KSG, Kang Shen Granular; TXT, Tian Xiang Tincture; KLT, Ke Tan Oral liquid; LL, Lingdancao Oral liquid; SKCG, Shijiaocao Ke Chuan Granular; WFSC, Wei Fu Shu Capsule; ZXASG, Zhi Xuan An Shen Granular; SAC, Shen An Capsule; HJXJC, Hong Jin Xiao Jie Capsule; SLAC, Shu Lie An Capsule; WJHXZTT, Wu Jin Huo Xue Zhi Tong Tablet; HSTT, Huzhang Shang Tong Tincture; GFNC, Gu Feng Ning Capsule; TYGT, Tianhusui Yu Gan Tablet; YSL, Yan Shu Oral liquid; WHXZTC, Wujin Huo Xue Zhi Tong Capsule; FFLC, Fu Fang Luxiancao Capsule; FFLG, Fu Fang Luxiancao Granular; NQSG, Niao Qing Shu Granular; YWNC, Yun Wei Ning Capsule.

successfully industrialized and modernized to promote the modern vitality of ancient ethnomedicines and thus serve a wide population range. The Tong Shu Capsule is a YPM produced by the Yunnan Baiyao Group that has been approved recently for phase II clinical research in the United States. Yunnan Province expects to produce TCMs including ethnomedicines with a value of 140 billion RMB in 2020 and an average annual growth of more than $15 \%$, accounting for $75 \%$ of its production [65].

Five key conclusions can be drawn from this investigation of Dai and Yi medicines.

First, except for the Yunnan Baiyao Group and the Dihon Pharmaceutical Company, most of the pharmaceutical manufacturers of EPMs in Yunnan Province are small enterprises, thereby limiting research and development capacity. A search on the China National Knowledge Infrastructure (CNKI, http://www.cnki.net) found 163 articles that reported investigations of these $28 \mathrm{DPMs}$ reviewed here and 59 articles about Yunnan Baiyao Aerosol, whereas it is only one of the CPMs produced by the Yunnan Baiyao Group. In 2015, 100 million bottles of Yunnan Baiyao Aerosol were produced, with a value of more 1.5 billion $\mathrm{RMB}$. In the same year, the overall sales revenue of the Yunnan Baiyao Group was 20.74 billion RMB [7].

Second, the sale volumes of YPMs and DPMs cannot be grasped, and it is hard to determine the extent to which traditional medicines used in YPMs and DPMs are collected in the wild. This will be a challenge to sustainable utilization for Chinese Materia medica resources.

Third, the use of toxic medicine used in ethnomedicine is of concern. Herbal medicine containing aristolochic acid has been associated with nephropathy in Belgium [66], and the adverse events associated with the use of Xiao Chaihu Tang in Japan [67] have led to warnings of the safety of CPM. Scientific evidence is needed to demonstrate the rationale and necessity of using toxic herbs in EPMs.

Fourth, the identification and usage of traditional medicines vary among ethnic minorities because of differences in experiences of clinical practice. The survey of DPMs and YPMs showed the differences in the number of animal sources of medicines used by the Yi and Dai people. The differences were also found in the ancient medical literature of Yi and Dai minorities.

Fifth, Dai and Yi medical prescriptions were traditionally written in the Dai and Yi languages, but the current clinical indications of DPMs and YPMs are written in Chinese. Difficulties in translation have hampered evaluation of how these ethnic medicines are used. Efforts to obtain accurate translations will be the next important work.

The sale volumes of DPMs and YPMs are not available because they belong to trade secrets. Because the descriptions of ethnic medical prescriptions in the ancient literature were written in Yi and Dai languages, they are hard to comprehend. However, the medical practices and culture of ethnic minorities have existed in Yunnan for thousands of years and have resulted in written records of more than 1300 ethnic medicinal materials and nearly 30,000 folk prescriptions. The medical information has been passed on orally or via ancient documents written in various ethnic minority languages such as the San Ma Tou Yi Medical Book and the Lao Wu Dou Yi Medical book written in the late Qing Dynasty of China. The ongoing scientific investigation and sustainable utilization of medicine resources will help to increase the impact of ethnomedicines of Yunnan Province on improvement of human health.

\section{Abbreviations}

CPM: $\quad$ Chinese patent medicine

ChP: $\quad$ Chinese Pharmacopoeia

CK: $\quad$ Creatine kinase

CR: $\quad$ Critically endangered

$\mathrm{Ca}^{2+}: \quad$ Calcium ion

DPM: $\quad$ Dai patent medicine

DDTN: Dan Deng Tong Nao Capsule

EM: $\quad$ Ethnic medicine

EN: $\quad$ Endangered

HT: $\quad$ High toxicity

IUCN: List of International Union for Conservation of Nature 


\begin{tabular}{|c|c|}
\hline LC: & Least concern \\
\hline LT: & Low toxicity \\
\hline LDH: & Lactate dehydrogenase \\
\hline LD50: & Median lethal dose \\
\hline i.v.: & Intravenous \\
\hline MP: & Medicinal parts \\
\hline MT: & Medium toxicity \\
\hline NPWP: & $\begin{array}{l}\text { National Key Protected Wild Plants of China } \\
\text { (Aug 4, 1999) }\end{array}$ \\
\hline NPWM: & $\begin{array}{l}\text { National Key Protected Species of Wild } \\
\text { Medicinal Materials of China (December 1, } \\
\text { 1987) }\end{array}$ \\
\hline NQS: & No quality standard \\
\hline NT: & Near threatened \\
\hline OTC: & Over-the-counter \\
\hline p.o.: & Per os \\
\hline RTCHYN: & $\begin{array}{l}\text { Rare Traditional Chinese Herbs of Yunnan } \\
\text { Province in Urgent Need }\end{array}$ \\
\hline RMB: & Renminbi \\
\hline Ref.: & Reference \\
\hline SYNP: & $\begin{array}{l}\text { Standards for Chinese medicinal materials in } \\
\text { Yunnan Province }\end{array}$ \\
\hline SPOP: & $\begin{array}{l}\text { Standards for Chinese medicinal materials in } \\
\text { other provinces }\end{array}$ \\
\hline SSDP: & $\begin{array}{l}\text { Standards for Chinese medicinal materials in } \\
\text { Shandong Province (2012) }\end{array}$ \\
\hline SSCP: & $\begin{array}{l}\text { Standards for Chinese medicinal materials in } \\
\text { Sichuan Province (2010) }\end{array}$ \\
\hline SGZP: & $\begin{array}{l}\text { Standards for Chinese medicinal materials in } \\
\text { Guizhou Province (2009) }\end{array}$ \\
\hline TCM: & Traditional Chinese medicine \\
\hline UF: & Usage frequency \\
\hline VU: & Vulnerable \\
\hline WHO: & World Health Organization \\
\hline YPM: & Yi patent medicine. \\
\hline
\end{tabular}

\section{Data Availability}

The data used to support the findings of this study are available from the first author upon request.

\section{Conflicts of Interest}

The authors declare that they have no conflicts of interest.

\section{Authors' Contributions}

HLQ conceived and designed the whole study and obtained funding. LZY conducted the data collection, interpreted the data, and drafted the manuscript. LCF drew the figures, and TSH evaluated the clinical indications. The herbal resource information was collected by ZXB and CXM. LZY and YHJ analyzed the data. HLQ reviewed and revised the manuscript.

\section{Acknowledgments}

The authors are very grateful for providing and authorizing them to use pictures of Rodgersia sambucifolia Hemsl. by
Professor Shaohua Yang (Institute of Alpine Economics and Botany of Yunnan Academy of Agricultural Sciences). The authors thank Mrs. Rong Yang (Faculty of Ethnomedicine, Yunnan University of Chinese Medicine) for providing some literature. This study was supported by the Major Science and Technology Projects of Yunnan Province of China (Grant no. 2017ZF004); Postdoctoral Directional Training Support Project of Yunnan Province; Accreditation Scheme from State Administration of Traditional Chinese Medicine (Grant no. GZY-KJS-2018-004); Open Subject from Jiangxi Collaborative Innovation Center of Modern Science and Technology and Industrial Development of Ethnic Minority Medicine (Grant no. JXXT2018005).

\section{Supplementary Materials}

Tables S1 and S2: in this article, all the ethnic patent medicines (EPMs) produced in Yunnan Province were collected. The information of these EPMs is obtained from the National Medical Products Administration of China, and all EPMs listed in the article have been checked according to open drug instructions. Table S1 and Table S2 provide the following information including the drug name, Chinese name, approval number, clinical indications, dosage form, and prescription status of Yi patent medicines (YPMs) and Dai patent medicines (DPMs). Some of these data supported the results of "clinical indications of Yi and Dai medicines" and Figure 1 in this article. Tables S3 and S4: in this article, the investigation focused on the composition of each EPM, the types of medicinal resources and medicinal parts, and quality standards for medicinal materials used in EPMs, including botanical, animal, and mineral resources. All these data are listed as two tables, showing separately the composition information and quality standards in DPMs (Table S3) and YPMs (Table S4). The information includes the drug name and pinyin name, Chinese name, scientific name, and medicinal parts of medicinal materials used in EPMs, and also contains the quality standard information of medicinal materials which can be regarded as the most important key supporting data for this article. (Supplementary Materials)

\section{References}

[1] R. S. Solecki, "Shanidar IV, a neanderthal flower burial in northern Iraq," Science, vol. 190, no. 4217, pp. 880-881, 1975.

[2] E. J. Buenz, R. Verpoorte, and B. A. Bauer, "The ethnopharmacologic contribution to bioprospecting natural products," Annual Review of Pharmacology and Toxicology, vol. 58, no. 1, pp. 509-530, 2018.

[3] A. K. Sharma, R. Kumar, A. Mishra, and R. Gupta, "Problems associated with clinical trials of Ayurvedic medicines," Revista Brasileira de Farmacognosia, vol. 20, no. 2, pp. 276-281, 2010.

[4] E. Yu and H. Amri, "China's other medical systems: recognizing Uyghur, Tibetan, and Mongolian traditional medicines," Global Advances in Health and Medicine, vol. 5, no. 1, pp. 79-86, 2016.

[5] Z. Zhu, T. Wang, D. Fu, Y. Gui, J. Wang, and T. Cui, "Innovative development path of ethnomedicines: an overview of 
ethnomedicines in China," Frontiers of Medicine, vol. 10, no. 2, pp. 166-177, 2016.

[6] L. Q. Huang, J. W. Lu, L. P. Guo et al., "Project design and implementation of the fourth national survey Chinese materia medica resources," China Journal of Chinese Materia Medica, vol. 38, no. 5, pp. 625-628, 2013, in Chinese.

[7] Q. X. Hu, Z. H. Jin, X. Li et al., "Suggestions on accelerating the development of biomedicine and health industry in Yunnan province," Yunnan Science and Technology Management, vol. 14, no. 1, pp. 8-10, 2017, in Chinese.

[8] Yunnan Provincial Government, Opinions of the People's Government of Yunnan Province on the Implementation of the Outline of Strategic Planning for the Development of Traditional Chinese Medicine (2016-2030), 2016, in Chinese, http:// www.yn.gov.cn.

[9] S. Y. Ma, H. Ren, C. H. Xu et al., "Curative effect evaluation of Dan Deng Tong Nao Capsule (DDTN) assisted rehabilitation training on convalescent stage of cerebral infarction," Chinese Journal of Practical Nervous Diseases, vol. 19, no. 19, pp. 98-99, 2016, in Chinese.

[10] D. Li, S. P. Wu, J. C. Hou et al., "Protective effect of Dandeng Tongnao Capsule (DDTN) on cerebral ischemia reperfusion rats," Chinese Pharmaceutical Journal, vol. 54, no. 20, pp. 1670-1676, 2019, in Chinese.

[11] Y. Y. Cheng, J. Y. Yu, L. Lin et al., "Statistics and analysis of ethnic medicine preparations in Chinese pharmacopoeia," Chinese Traditional Patent Medicine, vol. 39, no. 4, pp. 804808, 2017, in Chinese.

[12] J. Zheng, L. N. Guo, K. Zan et al., "General investigation report of quality standard status of ethnic medicines in nine provinces," Chinese Pharmaceutical Affairs, vol. 29, no. 12, pp. 1223-1235, 2015, in Chinese.

[13] R. Pu and D. R. Wan, "Investigation on Yi medical resources and their application and development," Asia-Pacific Traditional Medicine, vol. 23, pp. 18-21, 2017, in Chinese.

[14] E. M. Costa-Neto, "Animal-based medicines: biological prospection and the sustainable use of zootherapeutic resources," Anais da Academia Brasileira de Ciências, vol. 77, no. 1, pp. 33-43, 2005.

[15] X.-W. Zhou, L.-J. Li, and E.-W. Tian, "Advances in research of the artificial cultivation of Ophiocordyceps sinensisin China," Critical Reviews in Biotechnology, vol. 34, no. 3, pp. 233-243, 2014.

[16] Z. Shu, "Research, development, and industrialization of artificial musk: an overview," Acta Academiae Medicine Sinicae, vol. 36, no. 6, pp. 581-582, 2014.

[17] K. Y. Siu, N. Wang, K. M. Ng et al., "Bear bile: dilemma of traditional medicinal use and animal protection," Journal of Ethnobiology and Ethnomedicine, vol. 12, no. 5, pp. 1-9, 2009.

[18] Y. L. Wang, "Pharmacological experimental study on artificial and natural bear bile," Pharmacology and Clinics of Chinese Materia Medica, vol. 00, pp. 212-213, 1985, in Chinese.

[19] S. Y. Pan, G. Litscher, S. H. Gao et al., "Historical perspective of traditional indigenous medical practices: the current renaissance and conservation of herbal resources," EvidenceBased Complementary and Alternative Medicine, vol. 2014, Article ID 525340, 20 pages, 2014.

[20] G. A. Cordell and M. D. Colvard, "Natural products and traditional medicine: turning on a paradigm," Journal of Natural Products, vol. 75, no. 3, pp. 514-525, 2012.

[21] K. M. Wu, J. G. Farrelly, R. Upton, and J. Chen, "Complexities of the herbal nomenclature system in traditional Chinese medicine (TCM): lessons learned from the misuse of Aristolochia-related species and the importance of the pharmaceutical name during botanical drug product development," Phytomedicine, vol. 14, no. 4, pp. 273-279, 2007.

[22] F. J. Amu, Y. Li, L. B. Aya et al., "Investigation of naming regularity of Yi nationality medicine based on Yi nationality medicine theory," Journal of Guangzhou University of Trad itional Chinese Medicine, vol. 36, no. 9, pp. 1466-1470, 2019, in Chinese.

[23] Z. Y. Yan, "Major tasks and challenges for resources science of Chinese medicinal materials," Pharmacy Clinics of Chinese Materia Medica, vol. 3, no. 6, pp. 1-5, 2012, in Chinese.

[24] L. Q. Huang, L. P. Guo, G. H. Cui et al., "Basic theory research of traditional chinese medicine resources," Research and Information on Traditional Chinese Medicine, vol. 7, no. 8, pp. 4-6, 2005.

[25] X. W. Li, Y. N. Chen, Y. F. Lai et al., "Sustainable utilization of traditional Chinese medicine resources: systematic evaluation on different production modes," Evidence-Based Complementary and Alternative Medicine, vol. 2015, Article ID 218901, 10 pages, 2015.

[26] P. P. Li, H. L. Meng, Z. G. Meng et al., "Geographic distribution and habitat of Rodgersia sambucifolia in Yunnan province," World Science and Technology/Modernization of Traditional Chinese Medicine and Materia Medica, vol. 15, no. 1, pp. 120-125, 2013, in Chinese.

[27] Z. Q. Ouyang, S. Yang, L. J. Lu et al., "Current situation and counter measures of the rare and endangered plants protection in Yunnan," Environmental Science Guide, vol. 29, no. 5, pp. 31-35, 2010, in Chinese.

[28] D. Shaw, "Toxicological risks of Chinese herbs," Planta Medica, vol. 76, no. 17, pp. 2012-2018, 2010.

[29] Q. Xia, X. X. Zhang, K. X. Xu et al., "Review on toxicity of toxic traditional Chinese medicine recorded in Chinese pharmacopoeia (2015 version)," Global Traditional Chinese Medicine, vol. 10, no. 3, pp. 377-383, 2017, Chinese.

[30] X. Liu, Q. Wang, G. Song, G. Zhang, Z. Ye, and E. M. Williamson, "The classification and application of toxic ChineseMateria medica," Phytotherapy Research, vol. 28, no. 3, pp. 334-347, 2014.

[31] C. Zhang, V. Chongsuvivatwong, N. Keawptradub et al., "Analysis of prescription database extracted from standard textbooks of traditional Dai medicine," Journal of Ethnobiology and Ethnomedicine, vol. 8, no. 34, p. 6, 2012.

[32] J. Fang and J. X. Xu, "Development and application of Dai ethnic medicine "Jajie"” China Journal of Chinese Materia Medica, vol. 37, no. 14, pp. 2190-2192, 2012, in Chinese.

[33] D. R. Wan, Ethnic Toxic Medicine of China, Science Press of China, Beijing, China, 2016, in Chinese.

[34] Y. Nie, X. Dong, Y. He et al., "Medicinal plants of genus Curculigo: traditional uses and a phytochemical and ethnopharmacological review," Journal of Ethnopharmacology, vol. 147, no. 3, pp. 547-563, 2013.

[35] Y.-M. Li, M. Jia, H.-Q. Li et al., "Cnidium monnieri: a review of traditional uses, phytochemical and ethnopharmacological properties," The American Journal of Chinese Medicine, vol. 43 , no. 05 , pp. 835-877, 2015.

[36] W. N. Li, G. Xiao, D. Lu et al., " $\mathrm{LD}_{50}$ determination of osthole in mice," Journal of Modern Medical, vol. 29, no. 10, pp. 1444-1445, 2013, in Chinese.

[37] H. Hua, J. N. Zhao, L. C. Yan et al., "Study on toxicity spectrum and dose-response relationship of Cnidium monnieri (L.) Cuss," Pharmacology and Clinics of Chinese Materia Medica, vol. 28, no. 5, pp. 134-136, 2012, in Chinese.

[38] P. Wen, Q. T. Liu, Y. L. Gao et al., "Research progress on the zanthoxyli radix," Strait Pharmaceutical Journal, vol. 31, no. 1, pp. 30-31, 2019, in Chinese. 
[39] X. Ji, B. Huang, G. Wang, and C. Zhang, "The ethnobotanical, phytochemical and pharmacological profile of the genus Pinellia," Fitoterapia, vol. 93, pp. 1-17, 2014.

[40] J. Mu, "Research progress of amygdalin," Journal of Chinese Medicinal Materials, vol. 25, no. 5, pp. 367-368, 2002, in Chinese.

[41] G. Sandeep, A. Dheeraj, N. K. Sharma, D. Jhade, and A. Bharti, "Effect of plumbagin free alcohol extract of Plumbago zeylanica Linn. root on reproductive system of female Wistar rats," Asian Pacific Journal of Tropical Medicine, vol. 4, no. 12, pp. 978-984, 2011.

[42] S. Edwin, S. B. Joshi, and D. C. Jain, "Antifertility activity of leaves of Plumbago zeylanica Linn. in female albino rats," The European Journal of Contraception \& Reproductive Health Care, vol. 14, no. 3, pp. 233-239, 2009.

[43] Writing team of Chinese Herbal Medicine Compilation, Chinese Herbal Medicine Compilation in China, People's Health Press, Beijing, China, 1975, in Chinese.

[44] L. J. Yang, H. Y. Yu, P. Huang et al., "Study on the acute toxicity of Tripterygium hypoglaucum (Levl) Hutch solution in mice," Journal of Third Military Medical University, vol. 25, no. 17 , pp. 1524-1526, 2003, in Chinese.

[45] S. Z. Qian, Y. Z. Hu, S. M. Wang et al., "Effects of Tripterygium hypoglaucum (Lévl.) Hutch on male fertility," Advances in Contraception, vol. 4, no. 4, pp. 307-310, 1988.

[46] S. S. Cao and J. Du, "Research progress in toxicology of Evodia rutaecarpa (Juss.) Benth," Journal of Toxicology, vol. 31, no. 5, pp. 396-400, 2017.

[47] H. Ma, J. Zhou, J. Jiang et al., "The novel antidote Bezoar Bovis prevents the cardiotoxicity of Toad (Bufo bufo gargarizans Canto) Venom in mice," Experimental and Toxicologic Pathology, vol. 64, no. 5, pp. 417-423, 2012.

[48] R. Sun, H. Wang, W. Huang et al., "Experimental comparis on study on mice's acute toxicity of different composition in herba menthae," Chinese Journal of Pharmacovigilance, vol. 7, pp. 392-396, 2010, in Chinese.

[49] X. Miao, X. F. Zhang, D. D. Liu et al., "Research on toxicities and related models of aconiti Kusnezoffii radix," Traditional Chinese Drug Research \& Clinical Pharmacology, vol. 29, no. 6, pp. 836-839, 2018, in Chinese.

[50] J.-K. Kim, S.-H. Kim, S.-M. Lee et al., "Study of single-dose toxicity of aconitum kusnezoffii reichb. Pharmacopuncture in rats," Journal of Pharmacopuncture, vol. 15, no. 3, pp. 48-52, 2012.

[51] W. Tan, X. Y. Yang, L. Zhang et al., "The historical cognition and evaluation of Papaverispericarpium," Pharmacology and Clinics of Chinese Materia Medica, vol. 35, no. 2, pp. 159-162, 2019, in Chinese.

[52] G. Dong, J. Wang, P. Guo, D. Wei, M. Yang, and L. Kong, "Toxicity assessment of Arisaematis Rhizoma in rats by a $1 \mathrm{H}$ NMR-based metabolomics approach," Molecular BioSystems, vol. 11, no. 2, pp. 407-417, 2015.

[53] Y. N. Zhao, R. Wantana, B. Pisit et al., "Acute toxicity and antinocieptive effect of Laggera pterodonta (DC) Benth aqueous extract in mice," Natural Product Research and Development, vol. 17, no. 4, pp. 457-459, 2005, in Chinese.

[54] W. X. Wu, J. Y. Guo, Q. Wang et al., "Comparison study on acute toxicity of the aqueous solution from radix, radix with cortex and cortex of psammosilene tunicoides," Chinese Journal of Pharmacovigilance, vol. 2, pp. 457-459, 2016, in Chinese.

[55] W.-r. Xu, H.-s. Lin, X.-y. Chen, and Y. Zhang, "Yin-yang balance therapy on regulating cancer stem cells," Journal of
Traditional Chinese Medicine, vol. 31, no. 2, pp. 158-160, 2011, Chinese.

[56] L. X. Du, M. M. Luo, and S. M. Liu, "Research progress of modern toxicology on Dioscorea bulbifera L." Journal of Liaoning University of TCM, vol. 9, no. 3, pp. 71-72, 2007, in Chinese.

[57] Y. Sheng, Y. Ma, Z. Deng, Z. Wang, and L. Ji, "Cytokines as potential biomarkers of liver toxicity induced by Dioscorea bulbifera L," BioScience Trends, vol. 8, no. 1, pp. 32-37, 2014.

[58] X. J. Huang, H. Zhou, Y. Jiang et al., "Investigation of the toxicity of aconitum brachypodum Diels in vitro and in vivo," Journal of South-Central University for Nationalities, vol. 32, no. 4, pp. 51-68, 2013, in Chinese.

[59] Yunnan Yuxi Ethnic Affairs Commission, Ailao Materia Medica, Yunnan Nationalities Publishing House, Kunming, China, 1991, in Chinese.

[60] J. Zheng, C. Zhang, and Z. G. Qian, Yunnan Ethnic Medicine Dictionary, Shanghai Science and Technology Press, Shanghai, China, 2018, in Chinese.

[61] B. Z. Duan, J. Xu, H. T. Li et al., "Research status, development and utilization of traditional Dai medicine in China," China Journal of Chinese Materia Medica, vol. 40, no. 1, pp. 18-23, 2015, in Chinese.

[62] X. J. Ma, L. X. Zhang, and Y. F. Lin, Dai Medicine Records of China, People's Medical Publishing House, Beijing, China, 2018, in Chinese.

[63] Z. D. Zhang, J. P. Xu, and W. J. Sun, Yi Materia Medica, Yunnan Science and Technology Press, Kunming, China, 2019, in Chinese.

[64] B. L. Yang and H. X. Yu, Chinese Yi Medicine Prescriptions Science, Yunnan Ethnic Publishing House, Chinese, 2017.

[65] Institute of Traditional Dai Medicine of Xishuangbanna Dai Autonomous Prefecture, Study on Dai Classical Prescriptions of China, Yunnan Ethnic Publishing House, Kunming, China, Chinese, 2013.

[66] J.-L. Vanherweghem and J. Nortier, "Aristolochic acid nephropathy: a worldwide problem," Kidney International, vol. 74, no. 2, pp. 158-169, 2008.

[67] R. Teschke, A. Wolff, C. Frenzel, and J. Schulze, "Review article: herbal hepatotoxicity - an update on traditional Chinese medicine preparations," Alimentary Pharmacology \& Therapeutics, vol. 40, no. 1, pp. 32-50, 2014. 